\title{
Correction to: Grounding-Based Formulations of Physicalism
}

\author{
Jessica M. Wilson ${ }^{1} \mathbb{C}$
}

Published online: 28 February 2019

(c) Springer Nature B.V. 2019

\section{Correction to: Topoi (2018) 37:495-512 https://doi.org/10.1007/s11245-016-9435-7}

A number of ideas put forward in Sect. 5 of this article should be credited to an unpublished talk by Stephan Leuenberger: "Emergence and Failures of Supplementation". This talk, given on 26 May 2015 in Glasgow and attended by the author, developed an account of being strongly emergent as involving having partial but no full grounds. These ideas are: (i) The objection that the "orthodox" view of partial grounding does not allow for strong emergence, on such an account. (ii) The identification of one of Fine's non-orthodox notions of partial grounding as suitable for such an account. (iii) The use of the analogy to cases of weak supplementation failure in mereology to illuminate strong emergence and this nonorthodox notion of partial grounding. The author apologizes for neglecting to cite Leuenberger's work in her article, as she had intended to do.

Publisher's Note Springer Nature remains neutral with regard to jurisdictional claims in published maps and institutional affiliations.
The original article can be found online at https://doi.org/10.1007/ s11245-016-9435-7.

Jessica M. Wilson

jessica.m.wilson@utoronto.ca

1 University of Toronto, Toronto, Canada 